\title{
ПОЗДНЯЯ КОЖНАЯ ПОРФИРИЯ, ОСОБЕННОСТИ ПРОЯВЛЕНИЯ ПРИ ВИЧ - ИНФЕКЦИИ И ХРОНИЧЕСКОМ ВИРУСНОМ ГЕПАТИТЕ «С»
}

\section{LATE SKIN PORPHYRIA, FEATURES OF MANIFESTATION IN HIV INFECTION AND CHRONIC VIRAL HEPATITIS «C»}

V. Lavrenyuk

E. Ryazanova

Summary. The article presents an analysis of available data on the clinical features of late skin porphyria, which is formed in such pathological conditions as HIV infection and chronic viral hepatitis C. the Number of HIV-infected patients increases every year. In most cases, late skin porphyria is formed in these patients at a younger age. The selection of treatment options and recommendations was carried out taking into account the positive results of antiretroviral therapy. Positive dynamics of normalization of blood biochemical parameters in the course of treatment was established.

Keywords: late cutaneous porphyria, HIV infection, viral hepatitis C.
$\Pi$ оздняя кожная порфирия (ПКП) - системное хроническое заболевание, развивающееся в результате накопления в коже порфиринов (продуктов неполного биосинтезе гамма), что приводит к существенному нарушению нормальных функций эпидермиса и сбоям функционирования организма. Распространенность ПКП выше по сравнению с другими формами заболеваний, схожих по этиологии [1]. Особенность данного типа порфирии заключается в том, что $80 \%$ случаев ее развития являются приобретенными [2]. При развитии ПКП на открытых участках кожи наблюдается:

1. Появление прозрачных зудящих пузырей диметром до 10 мм, а затем эрозий, покрывающихся корками.

2. Меланоз (пигментация) и преждевременное старение (прогрессирует с течением времени).

3. Легкая травматичность.

Выделяют: кожную, кожно-висцеральную, кожно-нервную и смешанную формы ПКП. Последняя чаще развивается на фоне отягощенного анамнеза, в частности, у больных туберкулезом легких, алкоголизмом, сифилисом, малярией, бруцеллезом [4]. ПКП является типичным клиническим примером сопутствующего за-

\author{
Лавренюк Владимир Валерьевич \\ Ассистент, ФГБОУ ВО «Тихоокеанский \\ государственный Медицинский Университет» \\ lavrenyuk_90@bk.ru \\ Рязанова Елена Витальевна \\ Аспирант, ФГБОУ ВО «Тихоокеанский \\ государственный Медицинский Университет» \\ ryazanova_14@bk.ru
}

Аннотация. В статье представлен анализ имеющихся данных о клинических особенностях поздней кожной порфирии, которая формируется при таких патологических состояниях, как ВИЧ-инфекция и хронический вирусный гепатит С. Количество ВИЧ-инфицированных пациентов возрастает с каждым годом. В большинстве случаев поздняя кожная порфирия формируется у таких пациентов в более молодом возрасте. Подбор варианта лечения и рекомендаций проводили с учетом положительных результатов антиретровирусной терапии. Установлена положительная динамика нормализации биохимических показателей крови в процессе лечения.

Ключевые слова: поздняя кожная порфирия, ВИЧ-инфекция, вирусный гепатит С.

болевания у ВИЧ-инфицированных пациентов. Порфирия в данном случае чаще развивается как результат хронического гепатита С - стандартного фактора поражения печени на фоне ВИЧ [3]. Поэтому ВИЧ-инфекцию наряду с алкоголизмом также относят к причинам, провоцирующим развитие ПКП. Кроме вышеуказанных в перечень факторов риска включены [4-6]:

1. Длительный неконтролируемый прием гормональных препаратов эстрогенной структуры и препаратов железа.

2. Курение.

3. Дефицит витамина С и каротина.

4. Длительный контакт с нефтепродуктами и другими источниками ароматических гепатотоксических углеводородов.

Развитие ПКП на фоне ВИЧ-инфекции в основном имеет классические клинические проявления [6].

Накопление порфиринов в коже при развитии ПКП приводит к значительному повышению уровня ее фотосенсибилизции (высокой чувствительности к солнечному свету). Главная причина заболевания - повреждение печени, приводящего к нарушению биосинтеза гемма 


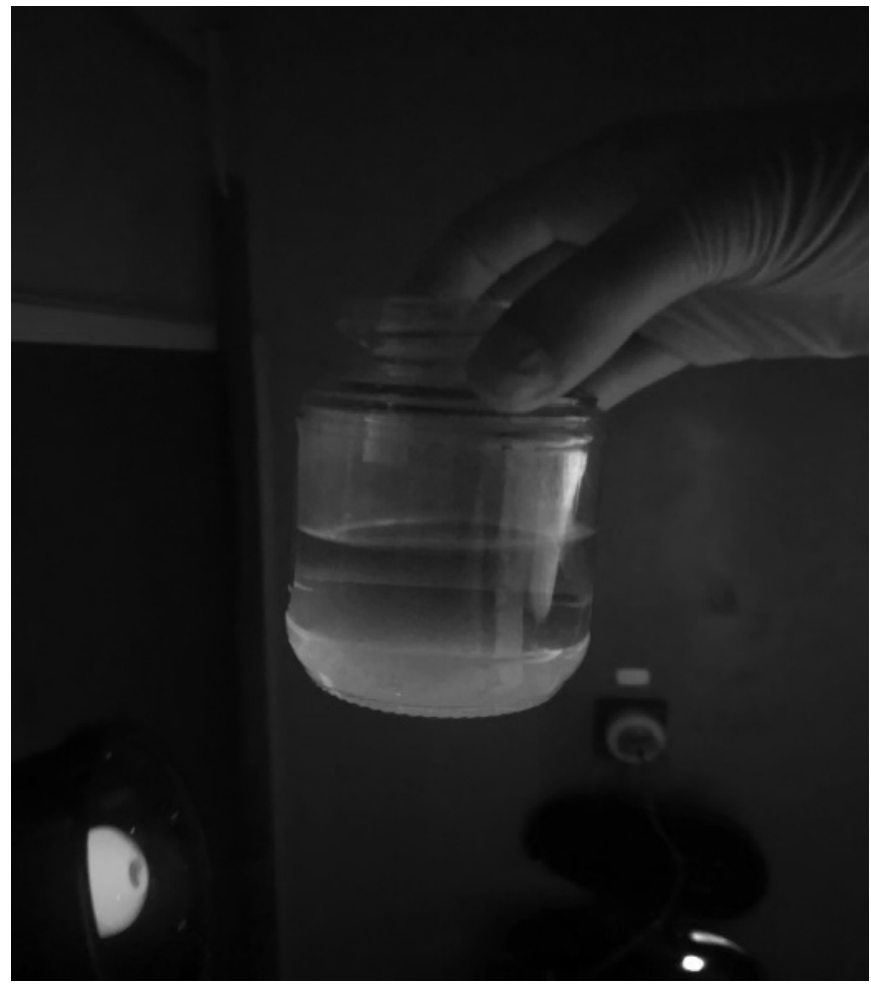

Рис 1. Моча с содержанием уропорфирина

вследствие снижения активности фермента уропорфириноген-ІІІ-декарбоксилазы [1, 7]. Провоцирующий фактор развития ПКП - диффузные изменения печени (поражения, затрагивающие весь орган), в частности в результате развития хронических поражений органа вследствие гепатита C, алкогольной интоксикации, отравления тяжелыми металлами, лекарственными и/или наркотическими препаратами [8].

Типичные показатели диагностики, указывающие на ПКП [7]:

1. Повышенное содержание уропорфирина на фоне нормы аминолевулиновой кислоты и порфобилиногена.

2. Кораллово-красное свечение мочи в лучах лампы Вуда. (Рис1,2)

3. Повышенное содержание аланинаминотрансферазы, аспартатаминотрансферазы и гамма-глютамилтранспептидазы в биохимическом анализе крови.

4. Высокая концентрация сывороточного железа.

Современные исследования, проводимые совместно с Федеральным научно-методическим центром по профилактике и борьбе со СПИДом, свидетельствуют о постепенном увеличении уровня заболеваемости ВИЧ-инфекцией. Причем заболеваемость возрастает ежегодно. Сложившаяся эпидемиологическая ситуация наносит

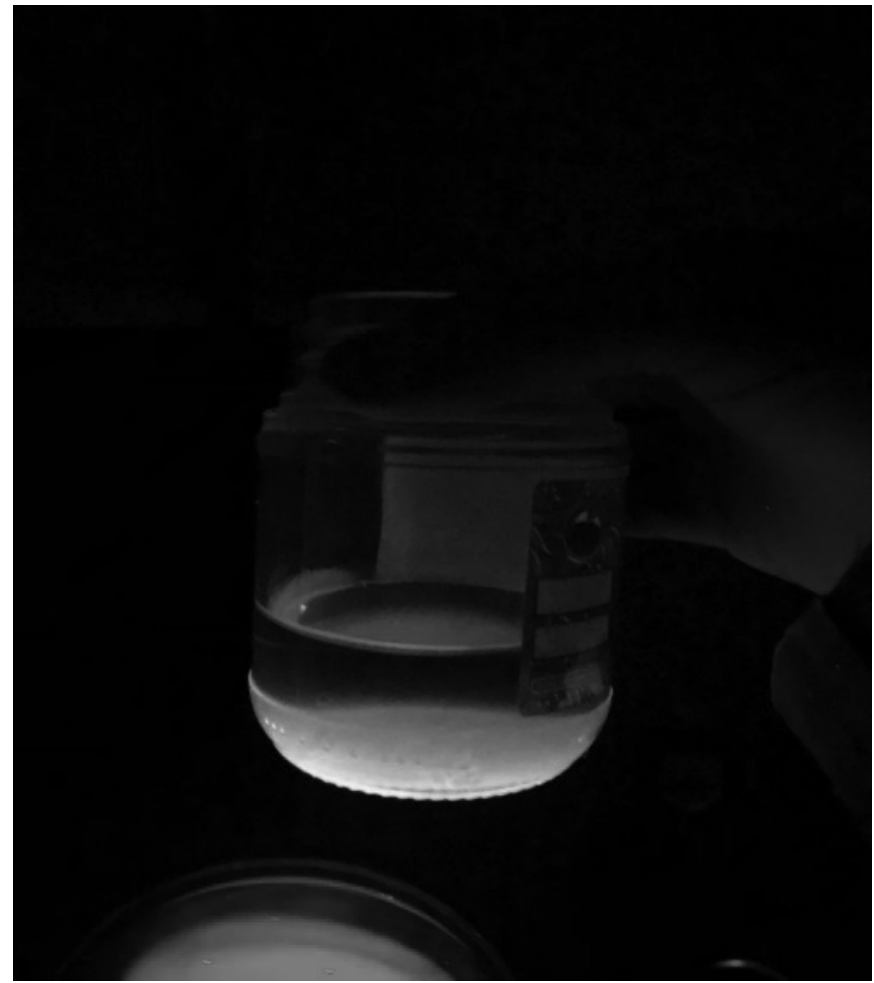

Рис 2. Моча в норме.

экономический и человеческий ущерб. Таким образом, можно обозначить ВИЧ-инфекцию как глобальную медицинскую и социальную проблему [5].

Согласно многочисленным клиническим и экспериментальным исследованиям, ВИЧ-инфекция характеризуется многолетним течением, в результате которого постепенно снижаются защитные свойства организма, он утрачивает свою естественную невосприимчивость к внешним факторам окружающей среды. Возникает поражение многих органов и систем. Таким образом, для каждого пациента с ВИЧ-инфекцией характерно определенное сопутствующее заболевание или комплекс дополнительных патологических процессов. Соответственно, такому пациенту назначается множество лекарственных препаратов одновременно, вызывая, тем самым, развитие местных побочных эффектов [10].

Поздняя кожная порфирия является наиболее распространенной формой нарушения пигментного обмена, патогенетическая причина которой заключается В нарушении выработки генов печени. В результате в большом количестве начинает синтезироваться уропорфирин и копропорфирин, их выделение происходит вместе с мочой, а также происходит накопление в коже. Согласно статистическим наблюдениям, патологическое состояние чаще всего встречается у мужчин в возрасте 40-50 лет [7]. 


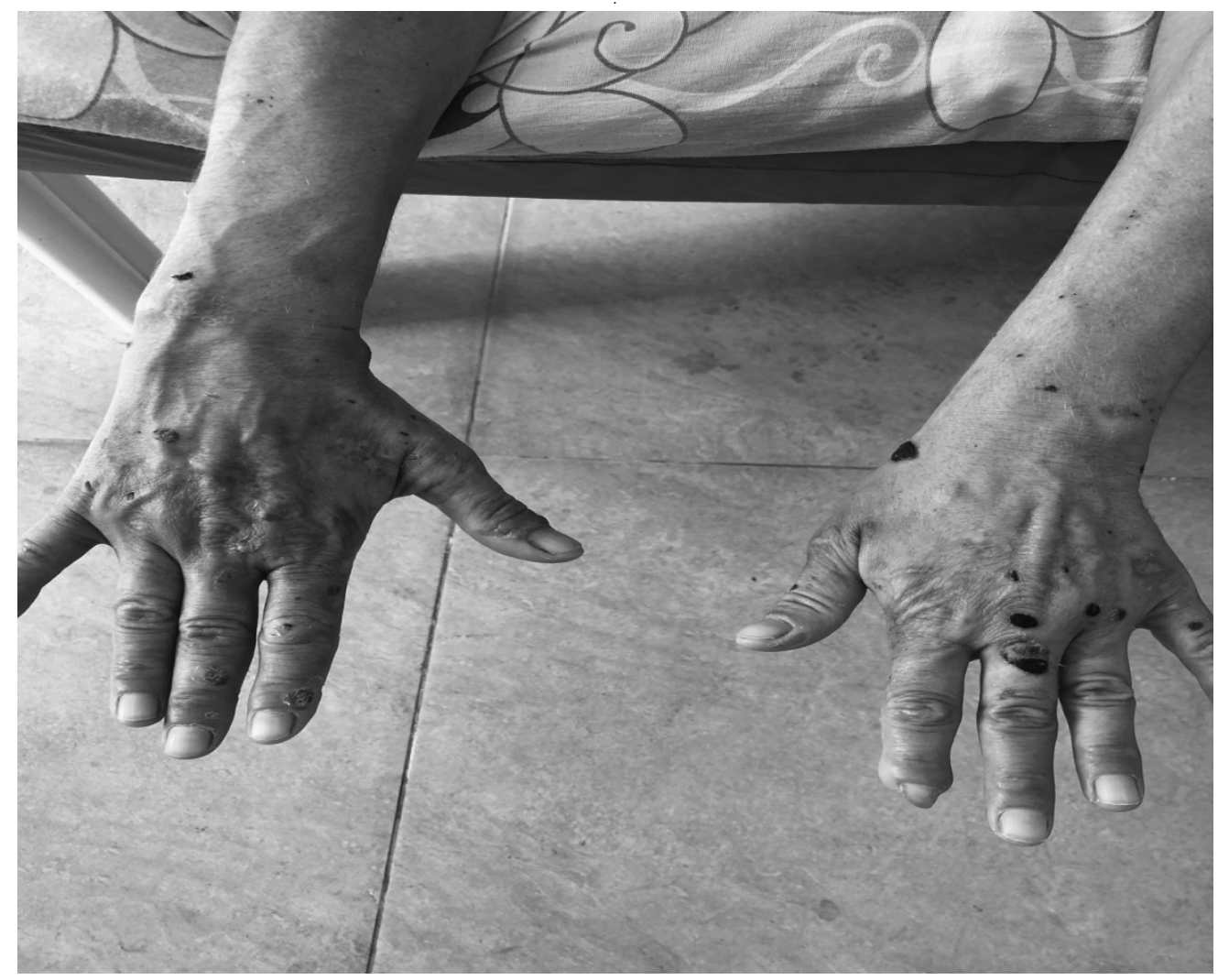

Рис. 3. Проявление ПКП на кистях рук.

Многочисленные экспериментальные наблюдения показали, что пациенты с ВИЧ-инфекцией отличаются достаточно ярко выраженной клинической картиной. В большинстве случаев отмечаются разнообразные поражения кожных покровов. В результате статистических наблюдений было отмечено, что поражения кожи среди пациентов с ВИЧ-инфекцией регистрируются в 90\% всех случаев, вне зависимости от сроков заболевания. Кожные патологические процессы отличаются большим разнообразием и тяжелой степенью течения [1]. Это обозначает актуальность исследования, поскольку данное патологическое состояние ухудшает качество жизни пациентов и снижает их работоспособность.

В результате клинических исследований было отмечено, что ВИЧ-инфекция в большинстве случаев осложняется присутствием хронического вирусного гепатита С. Это наиболее частая причина патологического состояния печени у пациентов с ВИЧ. Статистические наблюдения показывают, что у 20\% ВИЧ-инфицированных пациентов присутствует хронический вирусный гепатит С. В результате развития данного патологического комплекса резко снижаются защитные функции организма пациента, и, как результат, формируется поздняя кожная порфирия (спорадическая форма) [8].

\section{Материалы и методы исследования}

В результате клинических и экспериментальных исследований было установлено, что причина возникновения порфирии носит многофакторный характер. В процессе исследований отмечено, что ведущим фактором развития и прогрессирования поздней кожной порфирии является употребление алкоголя. Если не считать генетической предрасположенности развития данного патологического процесса, то порфирия обусловлена продолжительным токсическим действием на организм, в частности, многолетним употреблением большого количества лекарственных препаратов. Основа возникновения поздней кожной порфирии - наличие у пациента ВИЧ-инфекции. Статистические наблюдения показывают, что поздняя кожная порфирия диагностируется у 60$90 \%$ пациентов с активно протекающим хроническим гепатитом C [7].

Клинические особенности протекания поздней кожной порфирии достаточно ярко выражены. Это возникновение на открытых участках кожи специфических пузырей с прозрачным содержимым. Величина данных образований до 10 мм в диаметре, а наиболее частые места локализации - область лица и шеи, ушные раковины и тыльные части кистей. (Рис3). В дальнейшем, при 


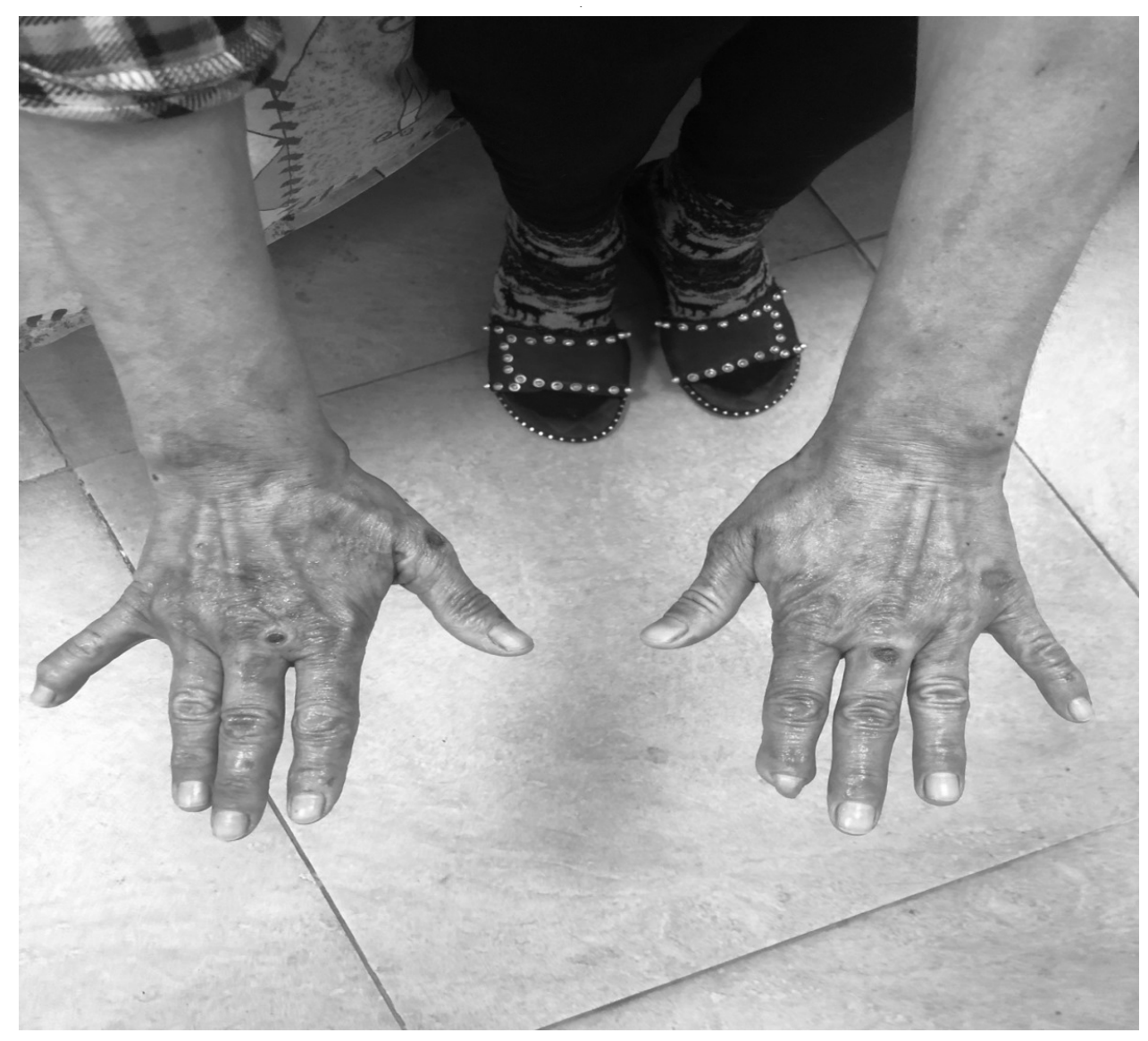

Рис. 4. ПКП после 2-х недельного курса терапии

вскрытии пузырей формируются эрозии с постепенным образованием корок. Сама кожа становится максимально чувствительна, даже к какой-либо легкой травме [1013].

Образование пузырей, характерное для поздней кожной порфирии, происходит после солнечного облучения, соответственно, заболевание имеет весенне-летнюю периодичность. Дальнейшее прогрессирование патологического процесса приводит к формированию морщин и возникновению преждевременных признаков старения кожи. Соответственно, такие пациенты выглядят старше своего биологического возраста. Отличительной особенностью поздней кожной порфирии является наличие фиолетово-коричневого окрашивания век, а после вскрывшихся пузырей на коже формируются атрофические поверхностные рубцы [6].

Поздняя кожная порфирия провоцирует поражение печени и нарушение функционирования желудочно-кишечного тракта, а также возникновение ожирения. Со стороны органа зрения возможны следующие нарушения: конъюнктивит, расширение сосудов глазного дна, помутнение роговицы, нарушение цветовосприятия [7].

При лабораторных исследованиях выявляется повышение активности аминотрансфераз, гамма-глутамилтрансферазы, гипергаммаглобулинемия, гиперпорфиринемия, гиперферремия. Патогномонично увеличение концентрации уропорфирина и копропорфирина I и III фракций.

В результате исследования клинических особенностей поздней кожной порфирии [3], было проанализировано состояние четырех пациентов с диагнозом ВИЧ-инфекция, у которых дополнительно была диагностирована поздняя кожная порфирия. Это 3 мужчины и 1 женщина в возрасте от 23 до 46 лет.

\section{Результаты и их обсужление}

В результате исследования была проанализирована длительность протекания заболевания - у трех пациентов кожная порфирия развивалась в течение 1-3 месяцев, у одного пациента клинические проявления заболевания наблюдаются около 2 лет. Обследование 
на наличие антител к ВИЧ показало, что они присутствуют у женщины и одного мужчины. Антитела к вирусу гепатита С обнаружены у пациентов-мужчин (3 человека). В результате сбора анамнеза было установлено, что все исследуемые пациенты злоупотребляли алкоголем и в течение последнего месяца были подвержены длительному воздействию ультрафиолетового облучения. Трое из четырех пациентов признались во внутривенном употреблении наркотических веществ. У двух мужчин и одной женщины поздняя кожная порфирия диагностирована впервые, у одного из мужчин данное патологическое состояние было диагностировано 2 года назад [3].

Клинические проявления поздней кожной порфирии у всех четырех пациентов носили классический характер. Наблюдалось формирование пузырей с серозно-геморрагическим содержимым, было выявлено наличие эрозий с серозными и геморрагическими корками, а также атрофические рубчики. Месторасположение данных патологических образований - открытые участки тела — лицо и шея, а также тыльная поверхность кистей [9].

В биохимическом исследовании крови у 3-х пациентов с вирусным гепатитом С имелось значительное повышение уровня печеночных трансфераз.

Терапевтические мероприятия у всех исследуемых пациентов заключались в следующем: гидроксихлорохина сульфат по 100 мг 2 раза в неделю, гепатопротекторы, витаминотерапия, местная обработка растворами антисептиков. Изучение динамики развития патологического процесса при проводимых терапевтических мероприятиях выявило, что через 2 недели после начала терапии у 3-х пациентов отмечался регресс высыпаний (Рис 4), у 1-го пациента сохранялись единичные элементы сыпи на тыле кистей [4].

Таким образом, поздняя кожная порфирия у пациентов с ВИЧ-инфекцией и вирусным гепатитом С имеет классические проявления заболевания и поддается терапевтическому воздействию стандартными методами, однако в большинстве случаев дебютирует в молодом возрасте, что может служить поводом для исследования таких пациентов на наличие антител к вирусу иммунодефицита человека.

\section{ВывO $\triangle \mathrm{b}$}

В конце лечения отмечено исчезновение кораллово-красного свечения мочи в лучах лампы Вуда, восстановился ее физиологический оттенок. В результате анализов выявлено исчезновение белка и уменьшение количества лейкоцитов до единичных клеток. Поздняя кожная порфирия характеризуется как достаточно распространенное сопутствующее заболевание при ВИЧ-инфекции и хроническом гепатите С. Данное патологическое состояние имеет весенне-летнюю периодизацию, что связано с максимальным ультрафиолетовым облучением в данное время года. В большинстве случаев от заболевания страдают мужчины. Использование иммуносупрессоров в терапии ВИЧ-инфекции уже показало свою эффективность [9]. Единичные исследования действия Гидроксихлорохина \выявили, что данный препарат эффективен в качестве иммуномодулятора только в комплексе с АРВТ, в результате такой двухкомпонентной терапии ВИЧ снижается опосредованная LPS/TLR иммунная активация и увеличивается процент CD4-T-клеток в MHO [12]. При использовании его как индивидуального агента увеличивается репликация вируса ВИЧ и происходит снижение числа CD4-Tклеток [11].

При сочетании ВИЧ-инфекции, гепатита «С» ПКП развивается только у отдельных пациентов в комплексе с токсическими факторами внешней среды (алкогольной интоксикации). Поэтому в случае дальнейшего присутствия повреждающего фактора в образе жизни пациента вероятна дальнейшая хронизация заболевания. Данное патологическое состояние диагностируют, исходя из ярко выраженной клинической картины и сбора анамнеза, дополнительно проводятся лабораторные исследования с целью выявления высокого уровня порфиринов

Клинические проявления поздней кожной порфирии носят ярко выраженный характер. Это возникновение на открытых участках кожи специфических пузырей с прозрачным содержимым. Величина данных образований до 10 мм в диаметре, а наиболее частые места локализации - область лица и шеи, ушные раковины и тыльные части кистей. В дальнейшем, при вскрытии пузырей формируются эрозии с постепенным образованием корок [8].

\section{ЛИТЕРАТУРА}

1. Карпова И.В., Сурин В. Л., Тагиев А.Ф., Пивник А. В./Лабораторная диагностика острой перемежающейся порфирии // Пробл. гематол. и перелив. крови. 一 2008. — № 1. - С. 43-48

2. Коротаева И.А., Скляр Л. Ф., Симакова А.И., Сингур Л.Г., Попов А.Ф. Псориаз и поздняя кожная порфирия, ассоциированная с хроническим гепатитом С при ВИЧ-инфекции (клинические наблюдения). Вестник дерматологии и венерологии. 2015. — (4): С. 90-94 
3. Потекаев Н.Н., Карпов Л. Л., Доля О. В., Маркова М. Н. Поздняя кожная порфирия как редкий случай внепеченочных проявлений хронического гепатита С у пациента, перенесшего сифилис // Клиническая дерматология и венерология. 2018. Т. 17, № 5. С. 119-127.

4. Немчанинова 0.Б., Бугримова А. А. Поздняя кожная порфирия у пациентов с ВИЧ-инфекцией / Немчанинова 0. Б., Бугримова А. А. // ГБОУ ВПО «Новосибирский государственный медицинский университет» Минздрава России (г. Новосибирск) 2ГБУЗ НСО «Новосибирский областной кожно-венерологический диспансер» (г. Новосибирск). - 2015.— № 3.- С. 42-48

5. Монахов С. А. Поздняя кожная порфирия / С. А. Монахов // Рос. журн. кожных и венерических болезней.— 2002.— № 5. — C. 83-85.

6. Тлиш М.М., Кузнецова Т. Г., Сычева Н. Л. Поздняя кожная порфирия: причины несвоевременной диагностики дерматоза // Клиническая дерматология и венерология. 2014. Т. 12, № 5. С. 92-97.

7. Уфимцева М.А., Канева Е. В., Худорожкова Н. П. Поздняя кожная порфирия // РМЖ. Дерматология. 2016. № 10. С. 651-654.

8. Vieira F. Porphyria cutanea tarda / F. Vieira, J. Martins // An. Bras. Dermatol. — 2006. — Vol. 81 (6). — P. 569-580.

9. Hepatitis C- and HIV-induced porphyria cutanea tarda / R. Quansah [et al.] // Am. J. Case.Rep. — 2014. — Vol. 21 (15). — P. 35-40.

10. Elder G.H./Enzymatic defects in porphyria: an overview.// Semin. Liv. Dis. — 2002. - 2.-p. 87-99

11. Lecha M., Herrero C., Ozalla D / Diagnosis and treatment of the hepatic porphyrias // Dermatologic Therapy, Vol. 16, 2003, 65-72

12. Murphy G.M / Diagnosis and management of the erythropoietic porphyries// Dermatologic Therapy, Vol. 16, 2003, 57-64

13. Thunell S./Porphyrins, porphyrin metabolism and porphyrias//Scand. J. Clin Lab Invest. — 2000.-60 (7).-p.509-540 cutaneous porphyria associated with chronic hepatitis C in HIV

○ Лавренюк Владимир Валерьевич ( lavrenyuk_90@bk.ru ), Рязанова Елена Витальевна ( ryazanova_14@bk.ru ).

Журнал «Современная наука: актуальные проблемы теории и практики»

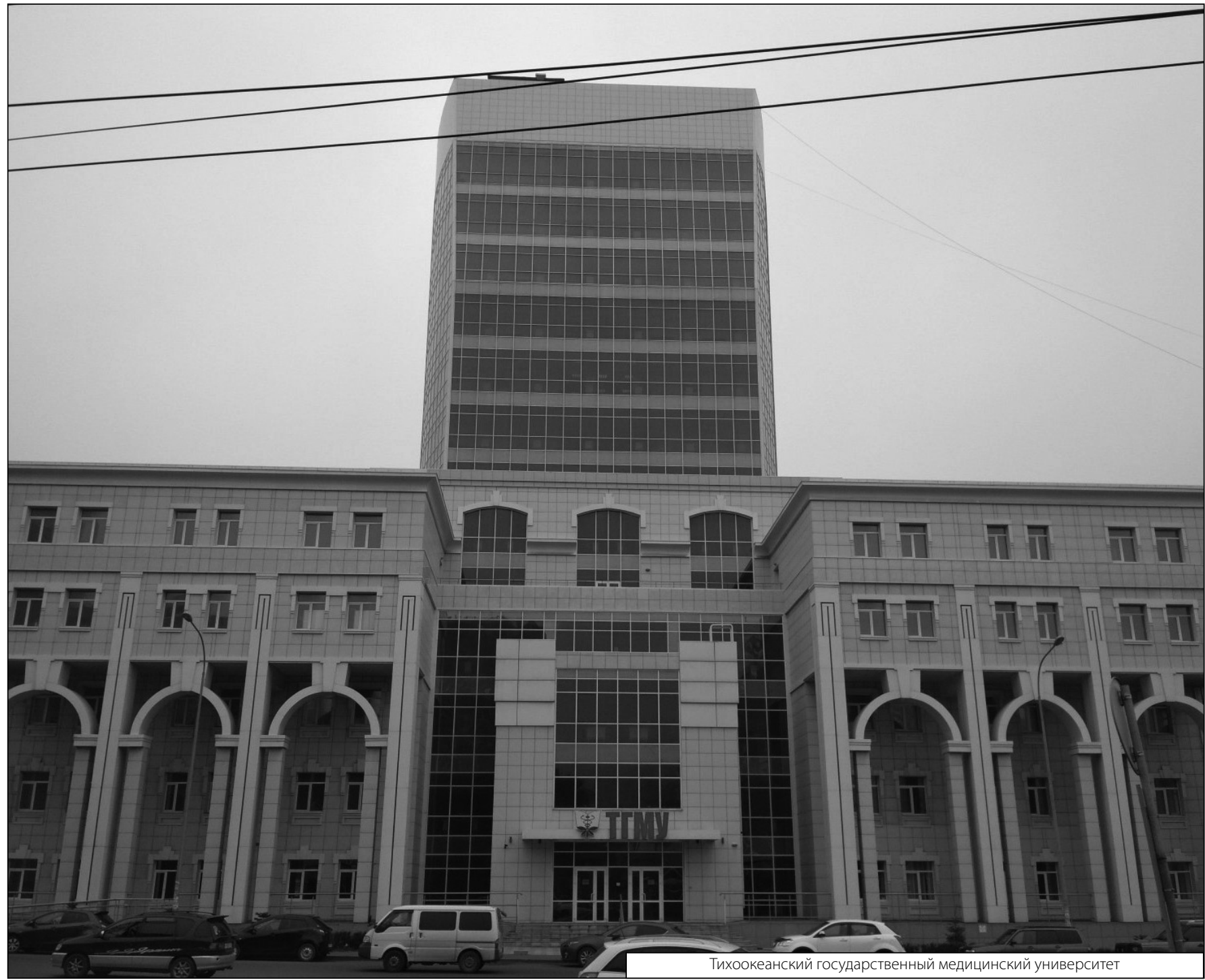

